\title{
THE ROLE OF SUPPORT ANTECEDENTS IN NURSES' INTENTIONS TO QUIT: THE CASE OF AUSTRALIA
}

\section{DESIGN HEADING: SUPPORT ANTECEDENTS AND QUITTING}

\begin{abstract}
Aims. The study used Social Exchange Theory as a lens to examine associations between nurses' support antecedents (supervisor-nurse relationships and perceived organizational support) and their job attitudes (job satisfaction, organizational commitment and engagement).
\end{abstract}

Background. Similar to many other westernized countries, there is a shortage of nurses working as nurses in Australia. The attrition of nurses from the workplace continues to be a challenge for many countries, with resultant calls for improved retention rates.

Methods. A self-report survey of 1600 nurses employed in five private sector hospitals throughout Australia was completed during 2010-11, resulting in 510 completed surveys.

Results. A mediation path model was developed to test the hypotheses and results of Partial Least Squares analysis showed that both support antecedents (supervisor-nurse relationships and perceived organizational support) positively led to engagement and job satisfaction. Subsequently, nurses more satisfied with their jobs were also more committed to their organizations, ultimately leading to lower intentions to quit. Additionally, job satisfaction was found to mediate the relationships between organizational commitment and turnover intentions, plus between supervisor-subordinate relationships and turnover intentions.

Conclusion. Within the context of a shortage of nurses and higher than average turnover rates, the findings suggest it is important to improve nurses' job satisfaction and organizational commitment in order to improve retention. However, the findings also 
suggest that workplace relationships and organizational management are currently far from ideal. 


\section{SUMMARY STATEMENT}

\section{Why is this research needed?}

- Nurse shortages challenge many countries, with Australia facing low numbers of entrants to the profession, high attrition rates and an ageing nurse workforce.

- Nurse retention is key to providing quality patient care and mitigating work overload in hospitals. Therefore, not surprisingly, retention of skilled healthcare labour is receiving increased attention.

- Effective nurse-supervisor relationships contribute to job satisfaction, organizational commitment and retention.

\section{What are the three key findings?}

- The primary finding targets nursing practice, confirming research in other industries about associations between perceived organizational support and supervisor-nurse relationships and job satisfaction, employee engagement, and intentions to quit.

- We found that workplace relationships, nurse engagement and job satisfaction, influenced intention to quit, plus we found mediation effects by affective commitment and job satisfaction.

- At a theoretical level, the key finding is that the social exchange context is a significant antecedent of engagement and job satisfaction.

\section{How should the findings be used for policy/practice/research/education?}

- Nursing needs management practices that deliver job resources that assist to better meet job demands. This is a people management problem which cannot be ignored. 
- The findings showing that nurses were only somewhat satisfied with relationships provide important managerial insight into a potentially growing problem in light of continuing productivity pressures and resource constraints.

- Associations between workplace relationships, engagement and job satisfaction mean there are turnover and associated cost implications for healthcare management, but they now have new knowledge to address such challenges.

\section{KEYWORDS:}

Job satisfaction, organizational commitment, perceived organizational support, supervisornurse relationship, employee engagement, intention to quit 


\section{INTRODUCTION}

Nurse retention is crucial because of current shortages in many healthcare workforces globally, combined with high turnover rates, ageing populations and lower entrant rates in countries like Australia. Employee engagement is being explored as one avenue for examining retention strategies. However, nurses face high workloads which, without supportive supervisor-nurse relationships, may lead to job dissatisfaction and turnover. Some researchers argue that job resources (provided by, for example, support from supervisors) may enhance engagement and mitigate employees' intentions to quit (Bakker et al. 2007).

Within the context of high workloads, Social Exchange Theory (SET) provides a framework for examining how high quality workplace relationships facilitate the reciprocal exchange of adequate resources (Cropanzano \& Mitchell 2005). Within the SET framework, numerous concepts are examined that measure different aspects of the value produced by workplace relationships, including perceived organisational support, leader-member exchange (LMX) and affective commitment.

While there is ample literature on supervisory support, leader-member exchange, and organizational support, there are few empirical studies focussing on the impact of support antecedents (supervisor-nurse relationships and perceived organisational support) upon engagement and job satisfaction. Hence, this paper provides new knowledge about these relationships for nurses. Further, scholars such as Williams and Hazer (1986) recommended that researchers incorporate commitment and job satisfaction when researching intention to quit, addressing previous research limitations, and providing further justification for the inclusion of these variables in our study.

\section{Background}


SET is argued to have 'the potential to provide a unitary framework for much of organisational behaviour' (Cropanzano \& Mitchell 2005, p.875). As stated, the basis of SET is that positive interactions lead to ongoing mutual reciprocity, as trust and commitment develop within the relationship. Under ideal circumstances, nurses develop such effective relationships with their supervisors (LMX) and their organisations (POS), and Cropanzano and Mitchell (2005) identified that LMX and POS were antecedents for many outcomes, as was affective commitment - another workplace relationship explained using SET.

Engagement is conceptualized in terms of emotional and intellectual involvement in creating a pervasive state of being, such that employees energetically undertake work tasks. However, debate remains about how to define and conceptualize engagement (Ferguson 2007). The psychological perspective suggests engagement as being the opposite of burnout (Isen 2003). However, Schaufeli and Bakker (2004) argue that burnout and engagement are generated by two different psychological processes and therefore cannot be viewed as a continuum. Using the Schaufeli and Bakker (2004) perspective, Saks (2006) conceptualized engagement using SET, arguing that reciprocity in balancing job demands and resources develops in employees who have received adequate support, resources, opportunities for promotion and other socio-emotional resources from their supervisor, leading to increased energy and dedication at work. Similarly, Shaw (2005) conceptualised engagement as part of a relationship between employees and their supervisors and/ or between colleagues and their organization. We adopt this perspective, using the SET lens to examine the impact of workplace relationships (such as the supervisor-nurse relationship) upon job attitudes for nurses, and subsequent influences on turnover intentions.

However, turnover intentions can be influenced by many factors, such as stressors, job demands, working conditions (shift work, number of hours), and lack of social, supervisory or organizational support, or career progression. We examine only some causes, to provide 
insight into whether supervisor-nurse relationships might 'cushion' nurses from organizational demands for increased efficiency and accountability.

SET has been used to examine the potential benefits of effective workplace relationships for the employee, supervisor and organization. The theory argues that when interactions between employees and their supervisors are perceived as "positive", over time, a relationship develops based on trust and consequently, participants in that relationship begin to exchange resources, knowledge, time and emotional support. Typical benefits of such positive relationships include access to relevant information, resources, support and participation in decision-making, interesting work assignments and greater control over workloads (Wang, et al. 2005; Yukl \& Michel 2006). Over time, an expectation based on reciprocal relationships, exchanging tangibles and intangibles, develops for some employees (Wang et al. 2005). When poor exchanges occur, a low-quality supervisor-subordinate relationship develops, characterised by low levels of reciprocity, plus interactions are limited to specific job tasks (Yukl \& Michel 2006).

Using the SET lens, in an ideal context, employees would experience high quality supervisor-nurse relationships and also perceive strong organizational support. Consequently, such nurses would perceive themselves as supported by their supervisors and organization, and that their resources match job demands. Consequently, they are likely to feel engaged (energetic and immersed) and committed to the workplace, leading to job satisfaction and low turnover intentions.

\section{Supervisor-nurse relationships}

Supervisor-nurse relationships can be conceptualized using Leader-Member Exchange theory (LMX). LMX theory is typical of workplace relationships examined using SET, and argues that supervisors do not manage all employees the same way because the quality of "social exchanges" differs between various employees. Consequently, some LMX 
relationships are high quality and characterised by a high level of mutual support, trust and respect (Gerstner \& Day 1997; Mueller \& Lee 2002), where staff appear to be liked by their supervisors, irrespective of their performance (Graen \& Uhl-Bien 1995). In ideal circumstances, management embeds high quality relationships between nurses and their supervisors, providing adequate job resources - information, support and participation in decision-making, access to interesting tasks, greater autonomy, promotions and bonuses. In return, supervisors receive dedicated employees who show initiative, plus provide extra support for supervisors' decisions (Wayne et al. 1997). In contrast, in poor quality work contexts, nurses are likely to face high job demands with inadequate job resources provided to cope effectively.

The LMX concept is useful in examining nursing because Ackroyd et al. (2007) argue the supervisor's role is pivotal in buffering with adequate job resources, those nurses facing high job demands. Using the SET theoretical lens, LMX theory suggests that the ideal situation is that all employees experience high-quality LMX because this delivers the greatest benefits to individuals and organizations. When supervisors are effective, they ensure that high job demands are countered by high job resources and consequently, employees are engaged and experience high job satisfaction, whereas poor quality LMX is probably characterised by job demands swamping employees until they become dis-engaged (Sparrowe \& Linden 1997; Yrie, et al. 2003).

\section{Perceived Organizational Support}

POS is defined as an employee's perception of the extent to which the organization s/he works for values the work s/he has done and cares about her/his job satisfaction (Allen, et al. 2003). Just like LMX, SET is often used to examine POS because it is also based on the idea of reciprocity between employees and organizations, and a reciprocal relationship 
between POS and LMX (Wayne, et al 1997). Research has identified supervisor support as an antecedent of POS, while high affective commitment and low turnover are workplace outcomes of high levels of POS (Wayne et al., 1997). Additionally Rhoades et al. (2001) argue that high POS predicts high perceptions of job satisfaction, whereas Saks (2006) argues that POS predicts the engagement of employees. In the case of nurses, where high job demands are an everyday occurrence, the importance of providing organizational support is vital in balancing competing demands (May, et al. 2004). Certainly, Saks (2006) suggests future research is needed to examine these relationships for different types of employees, and the impact of LMX and POS upon the engagement, job satisfaction, affective commitment and turnover intentions of nurses.

\section{Employee Engagement}

Schaufeli and Bakker (2004) defined employee engagement in terms of state of mind characterised by positive perceptions of fulfilling tasks. It is not surprising then that it is linked to job satisfaction (Harter et al. 2002). Past research suggests that the antecedents of employee engagement are effective leadership and co-worker relationships, interesting work tasks and effective job resources (e.g., May et al. 2004). Similarly, Richman (2006) argued that engagement is likely to be influenced more by management practices, the work environment and climate, than by the age, gender or the personality of employees. In the case of teachers, high job resources were found to be effective in providing a shield against high job demands (Bakker et al. 2007). Further, for fire fighters, engagement mediated the relationship between POS and performance, but other expected outcomes were not significant - 'job involvement, job satisfaction, and intrinsic motivation did not exceed engagement in explaining relationships among the antecedents and performance outcomes' (Rich et al. 2010, p.617). 
Because it is the organization's responsibility to provide a working environment that generates and maintains employee engagement, and because recent reforms have increased the job demands of workers (Brunetto et al. 2012), it is expected that the engagement of nurses will require high organization support as well as support from supervisors to ensure that job resources buffer job demands.

\section{Job Satisfaction}

Locke (1976, p.1304) defined job satisfaction as “... a pleasurable or positive emotional state resulting from the appraisal of one's job or job experiences". Previous research suggests that LMX affects job satisfaction (Epitropaki \& Martin 1999; Janssen \& van Yperen 2004; Han \& Jekel 2011), POS affects job satisfaction (Eisenberger et al. 1997) and job satisfaction affects affective commitment (Gerstner \& Day 1997). This is particularly important for nurses because POS indicates the extent to which an organization provides resources to assist employees to meet job demands and in so doing, contributes to overall job satisfaction (Rhoades \& Eisenberger 2002).

\section{Affective Commitment and Turnover Intentions}

Past research suggests a strong relationship between engaged and committed employees (Coffman \& Gonzalez-Molina 2002; Saks 2006). Committed employees are those engaged in the job (Meyer \& Allen 1991), who are emotionally attached to and identify with their workplace, and consequently, tend to stay working at the same organization. POS predicts affective commitment especially when combined with a perception of justice (Luchak \& Gellatly 2007; Reid et al. 2008), which is important because there is a link between employees' affective commitment and intention to leave (Meyer \& Allen 1997; Pitt et al. 1995). In the case of nurses, empirical studies exist examining factors such as the quality of 
the supervisor-subordinate relationship, stress and wellbeing influencing affective commitment of nurses (see Brunetto et al. 2011; Cohen 2006; Rodwell et al. 2009), and nursesupervisor relationships affect turnover intentions (Shacklock \& Brunetto 2011).

Further, nurses experience higher than average turnover levels (Buchan \& Calman 2004) and previous research identified a negative relationship between affective commitment and turnover intentions (Meyer \& Allen 1997; Meyer et al. 2002).

\section{Mediation Relationships}

We hypothesize that affective commitment mediates the relationship from job satisfaction to intention to quit. We have previously argued that there is a negative relationship between affective commitment and turnover intentions (Meyer et al. 2002). Similarly, when employees are dissatisfied with their job, they are more likely to want to quit (Han \& Jekel 2011). The mediation role of commitment on the job satisfaction to intention to quit relationship has previously been established by Williams and Hazer (1986). Results of path analysis showed that there is an association between job satisfaction and organizational commitment with high job satisfaction leading to high organizational commitment, leading to low turnover intentions (Williams \& Hazer 1986). Similarly, Yang (2008) found that committed employees have lower turnover intentions and high job satisfaction; reinforced by high organizational commitment. Tett and Meyer's (1993) meta-analysis confirmed that in some studies (for example, Clugston 2000), job satisfaction was a stronger predictor of intention to leave than organizational commitment.

The mediation effect of job satisfaction in the association between supervisor-nurse relationship and nurses' intentions to quit has not received much attention in the literature (Gerstner \& Day, 1997), with the exception of Han ad Jekel (2011). We have previously argued that LMX is positively related to employees' job satisfaction (e.g., Gerstner \& Day 
1997; Janssen \& van Yperen 2004) and Sagas and Cunningham (2004 cited by Han and Jekel 2011: 43) found that those people reporting high quality relationships with their supervisors also reported greater job and career satisfaction. Employees who were less satisfied with the quality of the relationships with their supervisors tended to want to quit their jobs (Graen \& Uhl-Bien 1995). Moreover, Han and Jekel's (2011) study concluded that high quality supervisor-nurse relationships led to reductions in nurses' intentions to leave. Therefore, we expect job satisfaction to mediate the association leading from LMX to turnover intentions.

\section{Hypotheses}

Based on the literature review, the current study will contribute to the literature by examining the strength and direction of the relationships from LMX and POS to engagement, job satisfaction, affective commitment, and turnover intentions (see Figure 1).

Hypothesis 1. Nurses who report higher levels of perceived organizational support will report higher levels of engagement.

Hypothesis 2. Nurses who report higher levels of perceived organizational support will report higher levels of job satisfaction.

Hypothesis 3. Nurses who report more positive exchange relationships with their supervisors will report higher levels of engagement.

Hypothesis 4. Nurses who report more positive exchange relationships with their supervisors will report higher levels of job satisfaction.

Hypothesis 5. Nurses who report more positive exchange relationships with their supervisors will report lower intentions to quit.

Hypothesis 6. Nurses who report higher levels of engagement will report higher levels of job satisfaction. 
Hypothesis 7. Nurses who report higher levels of job satisfaction will report higher levels of affective commitment.

Hypothesis 8. Nurses who report higher levels of job satisfaction will have lower intentions to quit.

Hypothesis 9. Nurses who report higher levels of affective commitment will have lower intentions to quit.

Hypothesis 10. Affective commitment mediates the relationship from job satisfaction to intentions to quit.

Hypothesis 11. Job satisfaction mediates the relationship between nurses' exchange relationships with their supervisors and their intentions to quit.

Insert Figure 1 about here

\title{
THE STUDY
}

\begin{abstract}
Aims
The aims of the study were to examine examine associations between nurses' perceived organizational support and supervisor-nurse relationships, with their job satisfaction, organizational commitment, engagement, and intentions to quit. To examine these associations, eleven hypotheses were tested.
\end{abstract}

\section{Design}

Based on the literature review, we used survey methodology via a self-report survey (Ghauri \& Grønhaug 2002) to test the hypotheses in Australia, collecting data during 2010-11. 


\section{Sample}

In Australia, $60 \%$ of hospital beds are provided by the public-sector and $40 \%$ by the private and non-profit sectors (Gee 2007). The nurses were from urban private hospitals, operating in acute clinical settings and experiencing similar patient case mixes. The hospitals comprised 3 medium (300-500 beds) and 2 large (>500 beds). To gather data, 1600 anonymous surveys were distributed to 5 hospitals selected for their mix of size and location, and nurses were invited to participate. The response was 510 useable surveys - an approximate response rate of $31.5 \%$.

\section{Data collection}

Anonymous surveys were sent to the hospitals with a detailed explanation sheet. As indicated in the survey information, informed consent was implied by respondents completing the survey. Reply-paid envelopes were provided to return the sealed surveys to the researchers. Nurses were invited to participate by flyers/advertisements in staff common rooms and were invited and reminded during normal staff meetings. No incentives were provided and assurances were given that no repercussions would result for not participating or for withdrawing.

Data were collected using a survey instrument containing 19 demographic measures (age, gender, position, employment status, and so on), and the items for each of six variables. Each item was measured on a six-point Likert-type scale, ranging from ' 1 '=strongly disagree, to ' 6 '=strongly agree.

Leader-Member Exchange. The leader-member exchange (LMX) validated test-bank survey traditionally measures the satisfaction of employees with the quality of the relationship with their supervisor-subordinate relationship (Mueller \& Lee 2002). In this study, a seven-item uni-dimensional scale (LMX-7), developed by Graen and Uhl-Bien (1995), was used. An 
example of a statement is, 'My nursing unit manager understands my work problems and needs'. This scale has good internal reliability as indicated by the composite reliability coefficient of 0.95 and an average variance estimate of 0.70 .

Perceived Organizational Support. Perceived organizational support was measured using the validated instrument by Eisenberger et al. (1997) (composite reliability coefficient of 0.79 and an average variance estimate of 0.57). Sample items included 'My organization cares about my opinion'.

Employee Engagement. We used a nine-item scale from Schaufeli and Bakker (2003) to measure Employee Engagement (reflective measure, composite reliability coefficient of 0.90 and an average variance estimate of 0.51 ). The sample items include, 'I find the work that I do full of meaning and purpose'.

Affective Commitment. We used the eight-item affective commitment scale from Allen and Meyer (1990) to measure nurses' commitment to their organizations. It was operationalized as a reflective measure and has a composite reliability coefficient of 0.87 and an average variance estimate of 0.68 . Sample items included "I feel a strong sense of belonging to my organization".

$\underline{\text { Job Satisfaction. }}$ To measure job satisfaction (formative measure), we adopted a four-item scale from by Johlke and Duhan's (2000) instrument. Sample items included, “I feel that my job is valuable". A formative scale was computed by forming an additive index of the four items.

Intention to Quit. We used a three-item scale adopted from Meyer, et al. (1993) to operationalize voluntary turnover intention (reflective measure), the dependent variable. This scale has a composite reliability coefficient of 0.91 and an average variance estimate of 0.78 . Sample items included "It is likely that I would search for a job in another organization". 


\section{Ethical considerations}

Ethics approval was gained from the university and hospital ethics committees. Voluntary participation was explained in the survey cover sheet and contact details of the researchers were provided in case of queries.

\section{Data analysis}

SPSSv.19 was used to conduct descriptive statistical analysis and exploratory factor analysis. SPSS AMOS 19.0 was used to check for common method variance analysis. Partial Least Squares Modelling, a form of latent path model, was used to test Hypotheses 1-9, while mediation analysis was conducted using the Sobel's test (Preacher \& Hayes 2004). SmartPLS v2 3.0 (Ringle, et al. 2005) was used to analyze the path model, which has five independent constructs and one dependent construct (sample size of 510 cases). According to Green (1991), this is considered sufficient to achieve a medium effect size of 0.80 for path analysis. Modelling was chosen as the statistical technique because it is considered suitable for the analysis of small samples and it does not require multivariate normal data (see Lee \& Tsang 2001). This technique has been recently published in Journal of Advanced Nursing (see Chang, et al. 2012) and allows the incorporation of formative constructs (Job Satisfaction is operationalized as a formative construct because all items are required to operationalize the formative nature of the construct, see Diamantopoulos, et al., 2008), unlike other covariancebased structural equation modelling techniques such as AMOS (see Chin, 2010). The software used in this study, SmartPLS (Ringle et al., 2005), allows the simultaneous determination of indirect and direct path influences among all of the latent variables in a model (www.smartpls.de) and has been published recently in the International Journal of Nursing Studies (Roche, et al. 2011). 


\section{Validity and reliability}

All tools used in this study were from previously validated test banks, and the reliability was tested via Cronbach's alpha scores (see Table 1). Significance of PLS parameter estimates was computed using the bootstrap option within SmartPLS. Bootstrapping with 500 subsamples was carried out to provide extra confidence that the results were not sample-specific. We undertook several tests to check for common method variance. The first test used Harman's ex-post one factor test (Podsakoff \& Organ 1986) by entering all of the items in the model into an unrotated factor analysis. The analysis showed that there were six factors (eigenvalues greater than 1.0) with the largest single factor explaining 37 percent of the variance. In addition, we conducted a common latent factor analysis using IBM SPSS AMOS 19. The analysis showed that the common variance was less than 7 percent, providing additional confidence that common method bias is not a major concern.

Discriminant validity of the reflective scales is confirmed because the square root of the AVEs is greater than the intercorrelation with the other constructs in the path model (Fornell \& Larcker, 1981). Validity of the formative scale was checked following Petter, et al. (2001). Multicollinearity was then checked by calculating the Variance Inflation Factors (VIFs) of the items composing the formative scale, and showed that multicollinearity is not an issue as the VIFs were less than 3.33 (Cenfetelli \& Bassellier 2009).

We evaluated the quality of the structural model by using R-square of the dependent variable, the Stone-Geisser Q-square test for predictive relevance (Chin 2010) and the global criterion for goodness of fit (Tenenhaus et al. 2005). Chin (2010) recommended that the communality and redundancy Q-square indices must be greater than zero, for the model to have predictive relevance. Two separate analyses with 7 and 25 omission distances were undertaken to test the stability of the findings. Since the values are stable for both omission 
distances and all of the Q-squares were greater than zero, we were confident that the model is stable and the predictive relevance requirement is satisfied.

\section{RESULTS}

The study respondents comprised 478 females and 32 males ranging in age from 19 to 67 years and with an average age of 46.5 years $(S D=10.4)$. In terms of job status, the sample included: (a) 110 Supervisors (who are all nurses), 281 Registered Nurses (RNs), 90 Enrolled Nurses (ENs) and 37 Nurse Assistants (AIN). ENs in Australia are nurses who care for people under the direction of registered nurses/physicians. AINs assist in the provision of basic nursing care, working within a plan of care under the supervision and direction of a registered nurse.

The model has discriminant validity as the correlation matrix shows that all the diagonal elements are greater than the corresponding off-diagonal elements (see Table 1). Using the formulae proposed by Tenenhaus et al. (2005) for calculating the global criterion of goodness of fit, the model has a large goodness of fit (global goodness of fit index of 0.51 ). In addition, the path model explained 44.6 percent of the dependent variable, Intention to Quit. Results of the path analysis are reported in Table 2. The path analysis showed that all of the paths leading from POS and LMX to turnover intention are statistically significant. Mediation analyses undertaken using the Sobel's test (Preacher \& Hayes 2004) showed that the mediation hypotheses were also supported. Hence, all of the hypotheses were supported.

\footnotetext{
Insert Tables 1 and 2 about here
}

\section{DISCUSSION}


The study is limited to nurses in one country and therefore further studies are required examining other types of employees, and in different countries. Other potential limitations were the exclusive investigation of private sector nurses, and self-report surveys potentially causing common methods bias. To reduce common method bias when the criterion and predictor variable cannot be measured in different contexts, as in this study, Podsakoff et al. (2003) recommend separating the measurement of these variables psychologically and ensuring the survey is anonymous. The survey applied these recommendations. Additionally, we conducted a Harmon's one-factor test and a common latent factor analysis using SPSS AMOS 19, providing additional confidence that common method bias is of no major concern. Further, our response rate $(31.5 \%)$ was below the accepted average for data collected from organizations - argued as being $35.7 \%$ with a standard deviation of 18.8 (Baruch \& Holtom 2008). Another limitation is that the two independent variables are likely to be affected by the data being nested within hospitals and within nursing units, plus hospitals are likely to have different levels of POS, and within each unit, LMX is likely to be influenced by the NUM of that unit.

This study first examined the impact of support antecedents (supervisor-subordinate relationships and perceived organizational support) upon the engagement, job satisfaction, organizational commitment and voluntary turnover intentions of nurses. Second, the paper examined the mediation effects of job satisfaction upon the relationship between LMX and turnover intentions, and of affective commitment between job satisfaction and intention to quit.

As stated, nursing was specifically chosen because first, nursing is a typical occupation with high emotional and physical demands (daily, when dealing with patients and their families) and second, nursing has been subject to reforms, increasing accountability and therefore nurses' workloads. Research has already identified the importance of the supervisor 
plus organizational management, in buffering nurses' high job demands with high job resources (Ackroyd et al. 2007; Brunetto et al. 2010; 2011). It was therefore expected that both LMX and POS would predict engagement and our findings confirm those expectations.

All eleven hypotheses were supported. The first two paths indicate that the higher the satisfaction with supervisor-nurse relationships and organizational support, the greater nurses' engagement. Both LMX and POS predicted job satisfaction and, as expected, engaged nurses also reported higher job satisfaction. Additionally, job satisfaction predicted both affective commitment and quitting intentions. This means that the higher nurses' perceptions of job satisfaction, the higher their organizational commitment and the lower their intentions to quit. Lastly, there was an inverse relationship between nurses' organizational commitment and intentions to quit. An important contribution of this paper is that it shows the links between workplace relationships, engagement and job satisfaction, and that enhancing these factors leads to improved organizational commitment and lower quitting intentions. Previous studies have used regressions to show relationships between these variables; however, regression does not provide a causal model.

There is a recognised shortage of nurses and poor management has been identified as one key reason (OECD, 2006). Previous research found that LMX and POS predict affective commitment and turnover (Rodwell et al., 2009; Brunetto et al., 2010, 2011). Consequently, our findings suggest that the impact of supervisor and organisational support is far from ideal. Specifically, nurses' perceptions of poor job support maybe one important factor contributing to our study's higher-than-average nurse turnover rate.

Consistent with previous research, our study found that nurses reporting high organizational commitment have lower turnover intentions and high job satisfaction. This finding corroborates the mediation hypothesis found in the literature (Williams \& Hazer 1986; Tett \& Meyer 1993; Yang 2008). Similarly, we found job satisfaction to partially mediate 
nurses' exchange relationships with their supervisors (LMX) and their turnover intentions. This finding confirms for nurses what other researchers (Han \& Jekel 2011) have identified that dissatisfied employees are more likely to want to quit their jobs. Supporting Han and Jekel (2011), we found that nurses who have a lower intention to quit, tend to have higher level of quality exchange relationship with their supervisors (LMX) and job satisfaction. That is, quality relationships between nurses and their supervisors are crucial in minimizing nurse turnover intentions. The partial mediation effect of job satisfaction is an important finding as it suggests that while LMX is an important antecedent of intention to quit, the level of job satisfaction also contributes to reduce nurses' on intention to quit. This mediation effect has not received much attention in the literature (Gerstner \& Day 1997).

The finding (that support antecedents do predict engagement and job satisfaction) has implications for management, because previous research suggests that management is key to determining job resources and therefore must be an antecedent of employee engagement (Harter et al. 2002; May et al. 2004; Bakker et al. 2007). Our findings suggest that this argument is also valid for nursing and with potential for wider healthcare implications globally. In theory, because nurses are professionals, they should get more support from their supervisors because of their shared professional knowledge and would have an expectation that supervisors will mentor them and attempt to mediate organizational and professional job demands (Farr-Wharton et al. 2011). However, our findings (based on the means) suggest that while these nurses perceived reasonably high quality relationships with their supervisors, they did not feel strongly supported by the organization generally; yet they reported remaining engaged, suggesting that supervisors were only partially able to mitigate the organizational demands on nurses.

\section{CONCLUSION}


In a global context of nurse shortages, calls for research to enhance retention strategies are common. This Australian study therefore sought to clarify the associations between nurses' support (supervisor-nurse relationships and perceived organizational support) in terms of their engagement, job satisfaction, commitment and turnover intentions. The findings confirmed that supervisor and organizational support predicted engagement and job satisfaction, as argued by SET. One contribution of the paper at a practical level is that it shows that when social exchanges are only barely effective, then nurses are only just engaged and somewhat uncommitted. This is hardly the ideal situation for occupations like nursing, irrespective of organization or country. The findings show that poor management of relationships could lead to less committed employees with higher intentions to leave, and the nurses in our study reported these characteristics, suggesting that present management practices may not be maximizing effective nursing outcomes.

At a theoretical level, the contribution of the findings is that the social exchange context is a significant antecedent of engagement and job satisfaction. In particular, this paper has identified the importance of the antecedents - supervisor and organizational support (Harter et al. 2002; May et al. 2004; Bakker et al 2007) - in predicting engagement and job satisfaction. Additionally, the SET framework was useful in identifying the perceived poor level of support provided by nurse management in the organization. SET also provided a framework for understanding why the nurse managers face retention challenges - poor levels of organizational support were perceived by the nurses. The findings therefore identify the need for nursing management to improve the quality of social exchanges, to provide greater support for ensuring that job resources match job demands, so that nurses are retained and high quality services can be delivered to the public. Finally, the findings provide new evidence of the mediating role of job satisfaction in the link between organizational commitment and intentions to quit, as well as supervisor-nurse relationships and 
organizational support, in the workplace. These findings may be applicable to international hospitals, where this new knowledge provides new perspectives on nurse management and retention. 


\section{REFERENCES}

Ackroyd, S., Kirkpatrick, I., \& Walker, R.M. (2007). Public management reform in the UK and its consequences for professional organization: A comparative analysis. Public Administration, 85, 9-26.

Allen, N. \& Meyer, J. (1990). The measurement and antecedents of affective, continuance, and normative commitment to the organization. Journal of Occupation Psychology, $61,1-18$.

Allen, D., Shore, L., \& Griffeth, R. (2003). The role of perceived organizational support and supportive human resource practices in the turnover process. Journal of Management, 29, 99-118.

Atencio, B., Cohen, J., \& Gorenberg, B. (2003). Nurse retention: Is it worth it? Nursing Economics, 21, 262-268.

Bakker, A. B., Demerouti, E., \& Verbeke, W. (2004). Using the job demands-resources model to predict burnout and performance. Human Resource Management, 43, 83104.

Bakker, A.B., Hakanen, J.J., Demerouti, E., \& Xanthopoulou, D. (2007). Job resources boost work engagement particularly when job demands are high. Journal of Educational Psychology, 99, 274-284.

Baruch Y \& Holtom B. (2008). Survey response rate levels and trends in organizational research, Human Relations, 61, 1139-1160.

Brunetto, Y., Farr-Wharton, R., \& Shacklock, K. (2010). The impact of supervisorsubordinate relationships on public and private sector nurses' commitment. Human Resource Management Journal, 20, 206-225. 
Brunetto, Y., Farr-Wharton, R., \& Shacklock, K. (2011). Supervisor-nurse relationships, teamwork, role ambiguity and job satisfaction: Public versus private sector nurses. Asia Pacific Journal of Human Resources, 49, 143-164.

Brunetto, Y., Teo, S., Shacklock, K., \& Farr-Wharton, R. (2012). Emotional intelligence, job satisfaction, wellbeing and engagement: Explaining organizational commitment and turnover intentions in policing. Human Resource Management Journal, 22(4), 428441.

Buchan, J., \& Calman, L. (2004). The global shortage of registered nurses: An overview of issues and actions. Geneva: International Council of Nurses.

Cenfetelli, R.T., \& Bassellier, G.B. (2009). Interpretation of formative measurement in information systems research. MIS Quarterly, 33, 689-707.

Chang, C., Huang, H., Chiang, C., Hsu, C., \& Chang, C. (2012). Social capital and knowledge sharing: effects on patient safety. Journal of Advanced Nursing, 68(8), 1793-1803.

Chin, W.W. (2010) How to Write Up and Report PLS Analyses, In V.E. Vinzi, W.W. Chin, J. Hen and H. Wang (Eds.), Handbook of Partial Least Squares: Concepts, Methods and Applications, pp. 655-90, Verlad Berlin Heilderberg: Springer.

Clugston, M. (2000). The mediating effects of multidimensional commitment on job satisfaction and intent to leave. Journal of Organizational Behavior, 21, 477-486.

Coffman, C., \& Gonzalez-Molina, G. (2002). Follow this path: How the world's greatest organizations drive growth by unleashing human potential. New York: Warner.

Cohen, J. (2006). The aging nursing workforce: How to retain experienced nurses. Journal of Healthcare Management, 51, 233-246.

Cropanzano, R., \& Mitchell, M.S. (2005). Social exchange theory: an interdisciplinary review, Journal of Management, 31, 874-900. 
Diamantopoulos, A., Riefler, P., \& Roth, K.P. (2008). Advancing formative measurement models, Journal of Business Research, 61, 1203-1218.

Eisenberger, R., Cummings, J., Armeli, S., \& Lynch, P. (1997). Perceived organizational support, discretionary treatment and job satisfaction. Journal of Applied Psychology, $82,812-820$.

Epitropaki, O., \& Martin, R. (1999). The impact of relational demography on the quality of leader-member exchanges and employees' work attitudes and well-being. Journal of Occupational and Psychology, 72, 237-240.

Farr-Wharton, R., Brunetto, Y., \& Shacklock, K. (2011). Professionals' supervisorsubordinate relationships, autonomy and commitment: A leader-member exchange theory perspective. International Journal of Human Resource Management, 22, 34963512.

Ferguson, A.E. (2007). Employee engagement: What it is, and how does it work in business and medical settings. Paper presented at the Australian Industrial and Organizational Psychology Conference: Better Work Better World, Adelaide.

Fornell, C., \& Larcker, D.F. (1981). Evaluating structural equation models with unobservable variables and measurement error. Journal of Marketing Research, 18, 39-50.

Gee, C. (2007). The contribution of the Australian private sector hospitals sector. Asian Pacific Journal of Health Management, 2, 41-46.

Gerstner, C., \& Day, D. (1997). Meta-analytic review of leader-member exchange theory: Correlates and construct issues. Journal of Applied Psychology, 82, 827-844.

Ghauri P. \& Grønhaug K. (2002) Research Methods in Business Studies: A Practical Guide. Pearson Education, Edinburgh. 
Graen, G., \& Uhl-Bien, M. (1995). Relationship-based approach to leadership: Development of leader-member exchange (LMX) theory of leadership over 25 years: Applying a multi-level multi-domain perspective. Leadership Quarterly, 6, 219-247.

Green, S.B. (1991). How many subjects does it take to do a regression analysis? Multivariate Behavioral Research, 26, 499-510.

Han, G.H., \& Jekel, M. (2011). The mediating role of job satisfaction between leader-member exchange and turnover intentions. Journal of Nursing Management, 19, 41-49.

Harter, J., Schmidt, F., \& Hayes, T. (2002). Business-unit-level relationship between employee satisfaction, employee engagement, and business outcomes: A metaanalysis. Journal of Applied Psychology, 87, 268-279.

Isen, A. M. (2003). Positive affect as a source of human strength. In L.G. Aspinwall, \& U.M. Staudinger (Eds.), A psychology of human strengths: Fundamental questions and future directions for a positive psychology: 179-195. Washington, DC: American Psychological Association.

Janssen, O., \& van Yperen, N. (2004). Employee's goal orientation, the quality of leadermember exchange, and the outcomes of job performance and satisfaction. Academy of Management Journal, 47, 368-384.

Johlke, M.C., \& Duhan, D.F. (2000). Supervisor communication practices and service employee job outcomes. Journal of Service Research, 3,154-165.

Lee, D.Y. \& Tsang, E.W.K. (2001), The Effects of Entrepreneurial Personality, Background and Network Activities on Venture Groups, Journal of Management Studies, 38, 583602.

Locke, E.A. (1976). The nature and causes of job satisfaction. In M.D. Dunnette (Ed.), Handbook of industrial and organizational psychology: 1297-1349. Chicago: Rand McNally. 
Luchak, A., \& Gellatly, I. (2007). A comparison of linear and nonlinear relations between organizational commitment and work outcomes. Journal of Applied Psychology, 92, 786-793.

May, D., Gilson, R., \& Harter, L. (2004). The psychological conditions of meaningfulness, safety and availability and the engagement of the human spirit at work. Journal of Occupational and Organizational Psychology, 77, 11-37.

Meyer, J., \& Allen, N. (1997). Commitment in the Workplace: Theory, Research and Application. Thousand Oaks: Sage Publications.

Meyer, J.P. \& Allen, N.J. (1991). A three-component conceptualization of organizational commitment. Human Resource Management Review, 1, 61-89.

Meyer, J.P., Stanley, D.J., Herscovitch, L., \& Topolnytsky, L. (2002). Affective, continuance, and normative commitment to the organization: A meta-analysis of antecedents, correlates, and consequences. Journal of Vocational Behavior, 61, 20-52.

Meyer, J.P., Allen, N.J., \& Smith, C.A. (1993). Commitment to organizations and occupations: extension and test of a three component conceptualization. Journal of Applied Psychology, 78, 538-551.

Mueller, B., \& Lee, J. (2002). Leader-member exchange and organizational communication satisfaction in multiple contexts. Journal of Business Communication, 39, 220-244.

OECD. (2006). Live Longer, Work Longer. Paris: Organization for Economic Cooperation and Development.

Petter, S., Straud, D., \& Rai, A. (2007). Specifying formative constructs in information systems research. MIS Quarterly, 31, 623-656.

Pitt, M., Leyland, F., Foreman, S.K., \& Bromfield, D. (1995). Organizational commitment and service delivery: Evidence from an industrial setting in the UK, International Journal of Human Resource Management, 6, 369-389. 
Podsakoff, P.M., \& Organ, D.W. (1986). Self-reports in organizational research: Problems and prospects. Journal of Management, 12, 531-544.

Podsakoff, P.M., MacKenzie, S.B., Lee, C.A., \& Podsakoff, N.P. (2003). Common method biases in behavioral research: A critical review of the literature and recommended remedies. Journal of Applied Psychology, 88, 879-903.

Preacher, K.J., \& Hayes, A.F. (2004). SPSS and SAS procedures for estimating indirect effects in simple mediation models. Behavior Research Methods, Instruments, and Computers, 36, 717-731.

Reid, M.F., Riemenschneider, C.K., Allen, M.W., \& Armstrong, D.J. (2008). Information technology employees in state government: A study of affective organizational commitment, job involvement, and job satisfaction. American Review of Public Administration, 38, 41-61.

Rhoades, L., Eisenberger, R., \& Armeli, S. (2001). Affective commitment to the organization: The contribution of perceived organizational support. Journal of Applied Psychology, $86,825-836$.

Rhoades, L., \& Eisenberger, R. (2002). Perceived organizational support: A review of the literature. Journal of Applied Psychology, 87, 698-714

Rich, B., Lepine, J. \& Crawford, E. (2010). Job Engagement: Antecedents and effects on job performance. Academy of Management Journal, 53(3), 617-635.

Richman, A. (2006). Everyone wants an engaged workforce how can you create it? Workspan, 49, 36-39.

Ringle, C. M., Wende, S., \& Will, A. (2005). SmartPLS 2.0 v.3 (beta); www.smartpls.de 
Roche, M., Duffield, C. \& White, E. (2011). Factors in the practice environment of nurses working in inpatient mental health: A partial least squares path modeling approach. International Journal of Nursing Studies, 48(12), 1475-1486.

Rodwell, J., Noblet, A., Demir, D., \& Steane, P. (2009). Supervisors are central to work characteristics affecting nurse outcomes. Journal of Nursing Scholarship, 41, 310 319.

Saks, A.M. (2006). Antecedents and consequences of employee engagement, Journal of Managerial Psychology, 21, 600-619.

Schaufeli, W. \& Bakker, A. (2003). UWES Utrecht Work Engagement Scale: Preliminary Manual, Utrecht: Utrecht University, Occupational Health Psychology Unit.

Schaufeli, W.B., \& Bakker, A.B. (2004). Job demands, job resources and their relationship with burnout and engagement: A multi-sample study. Journal of Organizational Behavior, 25, 293-315.

Schaufeli, W.B., Salanova, M., Gonzalez-Romá, V., \& Bakker, A.B. (2002). The measurement of engagement and burnout: A confirmative analytic approach. Journal of Happiness Studies, 3, 71-92.

Shacklock, K. H., \& Brunetto, Y. (2011). The intention to continue nursing: Work variables affecting three nurse generations in Australia. Journal of Advanced Nursing 68(1), 3646.

Shaw, K. (2005). An engagement strategy process for communicators. Strategic Communication Management, 9, 26-29.

Shore, L., Bommer, W., Rao, A., \& Seo, J. (2009). Social and economic exchange in the employee-organization relationship: The moderating role of reciprocation wariness. Journal of Managerial Psychology, 24, 701-721. 
Sparrowe, R., \& Linden, R. (1997). Process and structure in leader-member exchange. Academy of Management Journal, 22, 522-552.

Tett, R.P., \& Meyer, J.P. (1993). Job satisfaction, organizational commitment, turnover intention, and turnover: Path analyses based on meta-analytic findings. Personnel Psychology, 46, 259-293.

Tenenhaus, M., Vinzi, V.E., Chatelin, Y-M., \& Lauro, C. (2005). PLS Path Modeling, Computational Statistics and Data Analysis, 48, 159-205.

Wang, H., Law, K., Hackett, R., Wang, D., \& Chen, Z. (2005). Leader-member exchange as a mediator of the relationship between transformational leadership and followers' performance and organizational citizenship behavior. Academy of Management Journal, 48, 420-432.

Wayne, S.J., Shore, L.M., \& Liden, R.C. (1997). Perceived organizational support and leadermember exchange: A social exchange perspective. Academy of Management Journal, 40, 82-111.

Williams, L.J., \& Hazer, J.T. (1986). Antecedents and consequences of satisfaction and commitment in turnover models. Journal of Applied Psychology, 71, 219-231.

Yrie, A., Hartman, S., \& Galle, W. (2003). Examining communication style and leadermember exchange: Considerations and concerns for managers. International Journal of Management, 20, 92-100.

Yukl, G., \& Michel, J.W. (2006). Proactive influence tactics and leader member exchange. In C.A. Schriesheim \& L.L. Neider (Eds.), Power and influence in organizations: 87103. Greenwich, CT: Information Age Publishing.

Yang, J. (2008). Effect of newcomer socialisation on organisational commitment, job satisfaction, and turnover intention in the hotel industry. Service Industries Journal, 28, 429-443. 


\section{FIGURE 1}

Proposed Research Model of the influence of workplace relationships, engagement and job satisfaction upon nurses' intention to quit

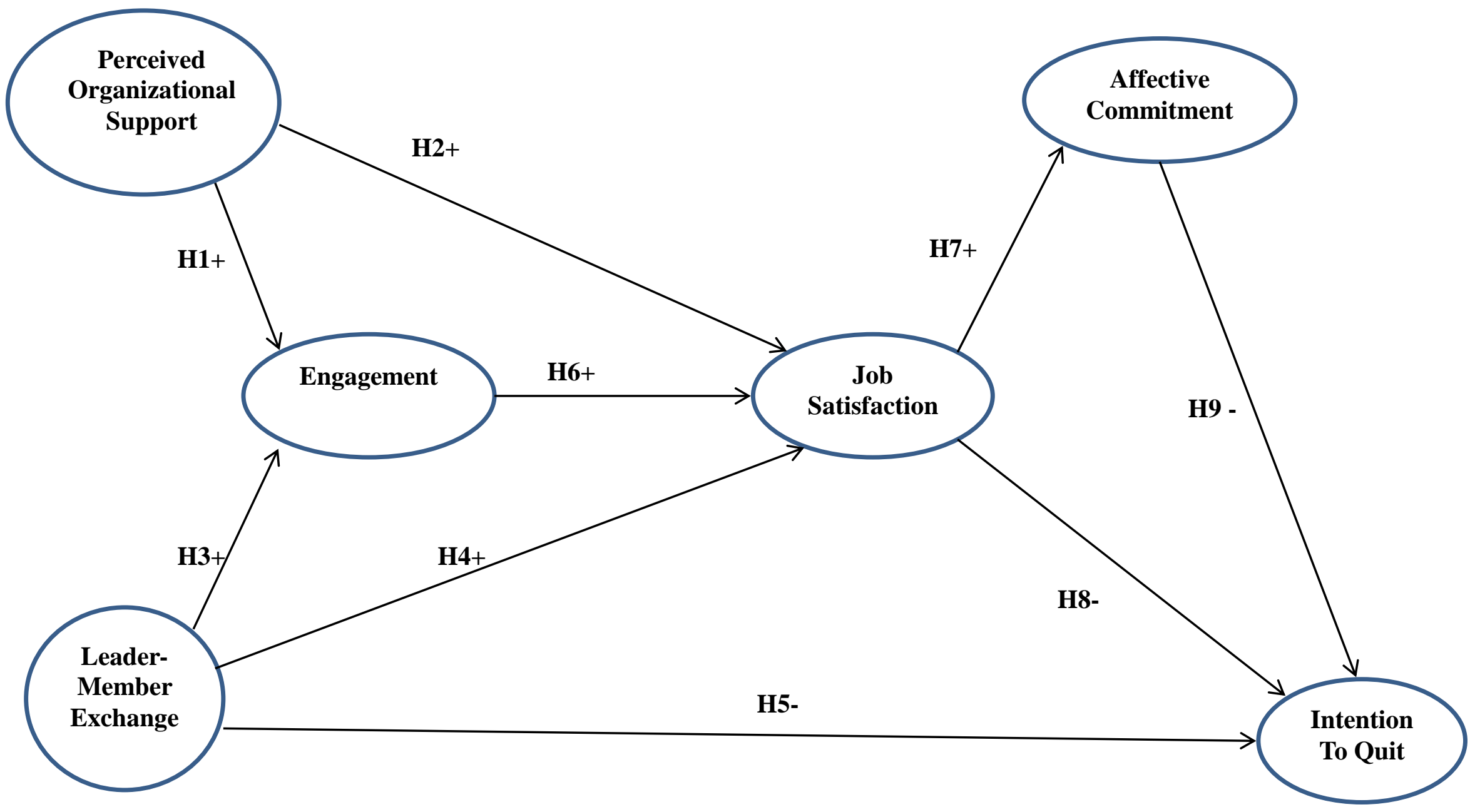

H10 -: Affective Commitment mediation hypothesis

H11 -: Job Satisfaction mediation hypothesis 


\section{TABLE 1}

Descriptive Statistics, Average Variance Estimates, Composite Reliability Coefficients and Intercorrelations for the study variables ${ }^{\text {a }}$

\begin{tabular}{|c|c|c|c|c|c|c|c|c|c|c|}
\hline & $\mathrm{M}$ & SD & $\alpha$ & AVE & 1 & 2 & 3 & 4 & 5 & 6 \\
\hline 1. Perceived Organizational Support & 3.84 & 0.64 & 0.79 & 0.57 & $\underline{0.76}$ & & & & & \\
\hline 2. Leader-Member Exchange & 4.65 & 1.00 & 0.95 & 0.70 & $0.43 * * *$ & $\underline{0.83}$ & & & & \\
\hline 3. Employee Engagement & 4.69 & 0.71 & 0.90 & 0.51 & $0.44 * * *$ & $0.34 * * *$ & $\underline{0.72}$ & & & \\
\hline 4. Job Satisfaction ${ }^{b}$ & 19.85 & 2.73 & -- & -- & $0.43 * * *$ & $0.48 * * *$ & $0.69 * * *$ & 1.00 & & \\
\hline 5. Affective Commitment & 3.97 & 0.87 & 0.87 & 0.68 & $0.53 * * *$ & $0.42 * * *$ & $0.60 * * *$ & $0.53 * * *$ & $\underline{0.83}$ & \\
\hline 6. Intention to Quit & 2.80 & 1.37 & 0.91 & 0.78 & $-0.39 * * *$ & $-0.43 * * *$ & $-0.50 * * *$ & $-0.46 * * *$ & $-0.60 * * *$ & $\underline{0.88}$ \\
\hline
\end{tabular}

a Six-point Likert-type scale, ranging from ' 1 '=strongly disagree to ' 6 '=strongly agree

b Job satisfaction is operationalized as a formative scale, computed by forming an additive index of the four items.

$\alpha$ Chronbach's alpha scores

Bold, underline and italicized figures denote Fornell and Larcker's (1981) discriminant validity check

$* * * \mathrm{p}<.001$ 
Table 2

Results of Partial Least Squares Path Analysis for the study hypotheses

\begin{tabular}{|c|c|c|}
\hline Hypotheses & $\begin{array}{c}\text { path } \\
\text { coefficient }\end{array}$ & t-statistic \\
\hline $\begin{array}{l}\text { Hypothesis } 1 . \text { Nurses who report higher levels of } \\
\text { perceived organizational support will report higher levels } \\
\text { of engagement. }\end{array}$ & 0.44 & $8.97 * * *$ \\
\hline $\begin{array}{l}\text { Hypothesis } 2 \text {. Nurses who report higher levels of } \\
\text { perceived organizational support will report higher levels } \\
\text { of job satisfaction. }\end{array}$ & 0.09 & $1.97 *$ \\
\hline $\begin{array}{l}\text { Hypothesis } 3 \text {. Nurses who report more positive exchange } \\
\text { relationships with their supervisors will report higher } \\
\text { levels of engagement. }\end{array}$ & 0.13 & $2.57 *$ \\
\hline $\begin{array}{l}\text { Hypothesis } 4 \text {. Nurses who report more positive exchange } \\
\text { relationships with their supervisors will report higher } \\
\text { levels of job satisfaction. }\end{array}$ & 0.34 & $6.88 * * *$ \\
\hline $\begin{array}{l}\text { Hypothesis } 5 . \text { Nurses who report more positive exchange } \\
\text { relationships with their supervisors will report lower } \\
\text { intentions to quit. }\end{array}$ & -0.17 & $3.67 * * *$ \\
\hline $\begin{array}{l}\text { Hypothesis } 6 . \text { Nurses who report higher levels of } \\
\text { engagement will report higher levels of job satisfaction. }\end{array}$ & 0.51 & $8.94 * * *$ \\
\hline $\begin{array}{l}\text { Hypothesis } 7 . \text { Nurses who report higher levels of job } \\
\text { satisfaction will report higher levels of affective } \\
\text { commitment. }\end{array}$ & 0.59 & $19.06 * * *$ \\
\hline $\begin{array}{l}\text { Hypothesis } 8 \text {. Nurses who report higher levels of job } \\
\text { satisfaction will have lower intentions to quit. }\end{array}$ & -0.12 & $2.15^{*}$ \\
\hline $\begin{array}{l}\text { Hypothesis 9. Nurses who report higher levels of affective } \\
\text { commitment will have lower intentions to quit. }\end{array}$ & -0.49 & $12.27 * * *$ \\
\hline $\begin{array}{l}\text { Hypothesis } 10 \text {. Affective commitment mediates the } \\
\text { relationship from job satisfaction to intentions to quit. }\end{array}$ & \multicolumn{2}{|c|}{ Sobel's test $=10.32 * * *$} \\
\hline $\begin{array}{l}\text { Hypothesis } 11 \text {. Job satisfaction mediates the relationship } \\
\text { between nurses' exchange relationship with their } \\
\text { supervisors and their intentions to quit. }\end{array}$ & \multicolumn{2}{|c|}{ Sobel's test $=2.05 *$} \\
\hline
\end{tabular}

